of publications and audio-visual materials in African public libraries; (iii) professional training for public library service. The group discussions were based on fifteen working papers prepared by librarians and educators working in Africa, and provisional study outlines drafted by the group leaders; these papers were circulated in advance of the meeting. In addition, each participant was asked to bring some statement on the public library service of his country and these were supplemented by reports on public library developments in seventeen African territories submitted by governments. A large collection of photographs of library services and mass education activities was placed on exhibition at Ibadan, and this to some extent compensated for the lack of a first-class modern public library in the locality. In addition, films on libraries, mass education, and other topics were shown, and arrangements were made for participants to visit the Gold Coast and see the public library service in that territory, which is centred in Accra with branches in several other towns, as well as mobile library services.

At the conclusion of the seminar a number of recommendations were drafted concerning the development of public library services in Africa, the organization and financing of such services, co-ordination between the various agencies producing publications for Africans so as to avoid duplication, training of library staff, formation of library associations, \&c. As one of the results of the seminar a West African Library Association was formed, with John Harris, Librarian of University College, Ibadan, as President, and representatives from Nigeria, Gold Coast, Sierra Leone, and Liberia on the Executive Committee.

\title{
Protectorate Literature Bureau (Sierra Leone)
}

THE Annual Report for 1953 records a widening of interest in efforts to achieve literacy, and an increasing demand for books in vernacular languages and in English. More and more Paramount Chiefs are co-operating in literacy campaigns which are now being carried out in twenty-six chiefdoms under the auspices of the Literature Bureau, and by welfare and community development workers in several districts. The total number of adults who have become literate in their own languages is now about 30,000. A number of books were published by the Bureau during the year, including school primers, children's books, portions of the Bible, proverbs and stories in Mende, Temne, Kono, and Kuranko. The number of books sold during the year was 39,117 , an increase of 5,291 on the previous record. 